\title{
Mathematical Investigation Proficiency among Singapore Secondary School Students: An Exploratory Study
}

\author{
Joseph B. W. YEO \\ National Institute of Education, Nanyang Technological University, Singapore \\ <josephbw.yeo@nie.edu.sg>
}

\begin{abstract}
This article presents an exploratory study to find out whether high-ability secondary school students in Singapore were able to deal with open mathematical investigative tasks. A class of Secondary One (or Grade 7) students, who had no prior experience with this kind of investigation, were given a paper-and-pencil test consisting of four open tasks. The results show that these students did not even know how to begin, despite sample questions being given in the first two tasks to guide and help them pose their own problems. The main difficulty was the inability to understand the task requirement: what does it mean to investigate? Another issue was the difference between searching for any patterns without a specific problem to solve, and searching for patterns to solve a given problem. The implications of these findings on teaching and on research methodologies that rely on paper-and-pencil test instruments will also be discussed.
\end{abstract}

Keywords: Mathematical investigation; open investigative tasks; thinking processes; research methodologies

\section{Background}

Mathematical problem solving is at the heart of the Singapore school mathematics curriculum and it includes "a wide range of situations from routine mathematical problems to problems in unfamiliar context and open-ended investigations" (Ministry of Education of Singapore, 2000, p. 10). However, most mathematics teachers in Singapore are only familiar with solving mathematical problems but they do not know much about mathematical investigation. Whenever I talked to teachers about mathematical investigation, many of them would look at me blankly and ask, "What is that?" (Yeo, 2008)

There are important thinking processes that can only be developed more fully when students engage in mathematical investigation (see next section). If teachers do not know what an investigation is, then they will not be able to develop these processes in their students (Frobisher, 1994). Thus I embarked on a research study to investigate the current proficiency in open investigation among secondary school students and to develop a teaching experiment to help students improve on their competency in investigation so that teachers can adopt a similar approach for their students. The original plan was to devise a paper-and-pencil test to study the nature of processes in open investigation and the current proficiency among a large sample of about 200 students (in width), and then design a teaching experiment based on the 
data collected to investigate the development of these processes among a small sample of about 30 students (in depth).

The first problem was the construction of a suitable test. I conducted a small study with a convenient sample of pre-service teachers to see if they could deal with open investigative tasks that contained no specific problems but ended with the word 'investigate' (Yeo, 2008). As expected, most of them were unable to begin because they did not understand the task requirement: what does the task want them to investigate? The implication was that most secondary school students might also have difficulty starting. Thus there was a need to modify the test instrument. If the students were given specific problems, then this would not be open investigation. So I thought of the idea of giving guided questions for the first two tasks and then no scaffolding for the last two tasks in the hope that students would know how and what to investigate for the last two open tasks. The first task with the guided question of finding as many patterns as possible was tried out on the same sample of pre-service teachers and this time all of them knew what to do.

In this article, I will outline an exploratory study where a class of high-ability students were given this test instrument in which the outcome was very surprising because most of the students could not even start on the first guided task! It revealed an important difference between a written test for open investigation and for problem solving, which has some serious implications for future research in this area. The study also shed some light on the current proficiency of Singapore secondary school students in open investigation.

\section{Literature Review}

Lee and Miller (1997) believed that "investigations, by their very nature, demand an open-minded, multifaceted approach" (p. 6) and Bailey (2007) asserted that a mathematical investigation is "an open-ended problem or statement that lends itself to the possibility of multiple mathematical pathways being explored, leading to a variety of mathematical ideas and/or solutions" (p. 103). Orton and Frobisher (1996) contended that mathematical investigation must be open in the sense that it should not contain any specified problems for students to solve, and so mathematical investigation involves both problem posing and problem solving (Cai \& Cifarelli, 2005). Although HMI (1985) stipulated that there is no clear distinction between mathematical investigation and problem solving, it still ended up 
separating them into two distinct activities: investigation is divergent while problem solving is convergent. Ernest (1991) also described problem solving as "trail-blazing to a desired location" (p. 285), but investigation as the exploration of an unknown land. However, Evans (1987) argued that if a student does not know what to do when faced with an investigation, then the investigation is still a problem to the student. Pirie (1987) alleged that no fruitful service would be performed by indulging in the 'investigation' versus 'problem solving' dispute, but I agree with Frobisher (1994) that this was a crucial issue which would affect how and what teachers teach their students.

Yeo and Yeap (2010) attempted to resolve this issue by suggesting that the term 'mathematical investigation' has different meanings. Just as Christiansen and Walther (1986) distinguished between a task and an activity, Yeo and Yeap (2010) asserted that investigation can refer to the task, the process or the activity. For example, an open investigative task is the Mathematical Investigative Task 3 shown in Figure 1 in the next section where no specified problems are given in the task statement and so the task is open for students to pose any problems to investigate; while a closed problem-solving task is the specific problem posed in part (a) of the Mathematical Investigative Task 2 shown in the same figure. When students attempt this kind of open investigative tasks, they are engaged in an open investigative activity, and this is consistent with the distinction made by Christiansen and Walther (1986) between a task and an activity. Thus an open investigative activity will involve posing and solving problems.

Yeo and Yeap (2010) also contended that posing a problem to investigate means that the student has not started the investigation, so there is a difference between investigation as an activity and investigation as a process. An analogy is Pólya's (1957) four stages of problem solving for closed problems or what is called problem-solving tasks in this article. During the first stage, the problem solver should try to understand the problem before attempting to devise a plan to solve it in the second stage. The third stage is carrying out the plan while the fourth stage is looking back after solving the problem. Another analogy is cooking. In order to cook (viewed as an activity), you need to prepare the ingredients before the actual cooking process, and you need to scoop up the food onto a serving dish after cooking. Similarly, in an open investigative activity, the students need to understand the task and pose a problem to investigate before engaging in the actual process of investigation. After the investigation, the students need to look back or they can pose more problems to 
investigate. Yeo and Yeap (2010) observed that the process of investigation usually involves examining empirical data or specific cases, formulating and justifying conjectures, and generalising. But these are the four core mathematical thinking processes advocated by Mason, Burton and Stacey (1985) for solving closed problem-solving tasks. Hence, Yeo and Yeap (2010) argued that investigation as a process can also occur when solving closed problem-solving tasks. It is noteworthy that Jaworski (1994) also viewed an investigative approach to mathematics teaching as involving specialising, conjecturing, justifying and generalisation when she observed that "making and justifying conjectures was common to all three [investigative] classrooms, as was seeking generality through exploration of special cases and simplified situations" (p. 171).

However, there are some processes that students can develop more extensively in open investigation than in closed problem-solving. For example, problem posing is one of the primary foci of open investigation because students cannot start to investigate unless they know how to pose a suitable problem, but students can solve a problem-solving task without posing any problem. Another example is the difference, as suggested by the present study, between searching for any patterns in an open investigation where there is no specific problem to solve and searching for patterns to solve a problem-solving task.

Presently, there are a lot more research studies on problem solving than on open investigation. But many of the latter (e.g. Ng, 2003; Tanner, 1989) only dealt with the general benefits of investigation without examining in details the actual thinking processes that students engage in when they do investigation. Therefore, there is a big research gap in studying the processes in open investigation, even though open investigation is emphasised in many school curricula, e.g. the Cockcroft Report in the United Kingdom (Cockcroft, 1982) and the Australian national curriculum (Australian Education Council, 1991). Hence, there is a need for more research in this area, and the present exploratory study is part of a bigger research project to investigate the nature and development of processes in open investigation with the purpose of informing teachers on how to cultivate these processes in their students. 


\section{Methodology}

It was decided that the sample should consist of high-ability students with no prior experience in this kind of open investigation as I needed the high-ability students to provide me with a wider range of possible thinking processes to plan for future research in this area. Thus a convenient intact class of 29 high-ability Secondary One (or Grade 7) students from a top secondary school in Singapore was selected. It is important to note that these students did not belong to the Gifted Education Programme (GEP) because the latter were more likely to encounter this type of investigation. This was further confirmed from a written survey conducted at the end of the paper-and-pencil test where all the students in the sample wrote that they had not seen this kind of open investigative tasks before. The written survey also asked for the students' Primary School Leaving Examinations (PSLE) score. Twenty of the 29 students (or 69\%) had a PSLE score of 253 to 255 (i.e. they were in the top $1 \%$ of the entire primary school cohort in Singapore), five students scored between 242 and 249, and three students scored between 230 to 239 . The last student did not write his score.

The written test consisted of four investigative tasks (see Fig. 1) to be completed individually within one hour and thirty minutes. As explained in the first section, the first two tasks had guiding questions while the last two tasks were more open. The first and third tasks are on number patterns, while the second and fourth tasks are 'word problems' (i.e. problems with a context) that have been made more open by asking students to investigate further. The test was administered by me. 
Mathematical Lnvestigative Task 1: Powers of a Number

$9^{5}$ means 9 multiplied by itself 5 times, i.e. $9^{5}=9 \times 9 \times 9 \times 9 \times 9=59049$.

Powers of 9 are $9^{1}, 9^{2}, 9^{3}, 9^{4}, 9^{5}, 9^{6}$, etc.

Investigate the powers of 9 .

For example, you can investigate the following or you can pose your own problems to investigate:

(a) Find as many patterns as you can about the powers of 9 .

(b) Explain why these patterns occur.

(c) Do these patterns occur for powers of other numbers?

\section{Mathematical Investigative Task 2: Basketball Tournament}

In a basketball tournament, each team must play against every other team once.

(a) How many matches will there be if there are 20 teams in the tournament?

(b) What else do you want to investigate? When you pose a question to investigate, write it down first.

\section{Mathematical Investigative Task 3: Polite Numbers}

Natural numbers are positive whole numbers: $1,2,3,4, \ldots$

Polite numbers are natural numbers that can be expressed as the sum of two or more consecutive natural numbers. For example,

$$
\begin{aligned}
9 & =2+3+4=4+5 \\
11 & =5+6 \\
18 & =3+4+5+6 .
\end{aligned}
$$

Investigate.

\section{Mathematical Investigative Task 4: Amazing Race}

In a 100 -metre race, Ali beats Bernard by 10 metres. The two boys plan to have another race (where both boys will still run at the same rate as before). Bernard sugge sts that he should be given a head start: he wants to start 10 metres in front of the start line while Ali still starts at the starting line. However, Ali disagrees. He suggests that he (Ali) will start 10 metres behind the start line while Bernard still starts at the start line.

(a) Investigate whether there is any difference between the two options.

(b) If you are Bernard, suggest some other options to Ali where you will have a slight advantage over him. (If you have a big advantage, Ali will not race with you.)

Figure 1: Mathematical Investigative Tasks for Test Instrument

Two types of scoring rubrics were developed: one to analyse how and the other to analyse what students investigated. The rubrics were task-specific, so there were two rubrics for each task, but the descriptors for each type of rubric were the same, except for the exemplars. Table 1 shows the first rubric describing how students investigated Task 1 . There 
were five levels. For example, in Level $1 \mathrm{H} 0$, the first number refers to the task number, the letter $\mathrm{H}$ stands for How and the last number refers to the level. Although some students did evaluate some powers of 9 , they either did nothing after that or they could not even find the simplest patterns, thus suggesting that they did not know how to investigate and so they should be classified under Level 1H1. This is different from students who knew how to investigate by evaluating powers of 9 and finding some patterns, which is Level $1 \mathrm{H} 2$. If students did not realise that the patterns that they have discovered are just conjectures, then they will be placed under Level $1 \mathrm{H} 2$. If they recognised that the observed patterns are conjectures but did not test them, they will be classified under Level 1H3. The highest level $1 \mathrm{H} 4$ is reserved for students who try to test conjectures even if they are not be able to prove or refute the conjectures.

Table 1

A Scoring Rubric to Describe How Students Investigated Task 1

\begin{tabular}{llcc}
\hline Level & Descriptors and Exemplars & $\begin{array}{c}\text { No. of } \\
\text { Students }\end{array}$ & Percentage \\
\hline 1H4 & $\begin{array}{l}\text { Students knew how to investigate by testing conjectures and } \\
\text { generalising. }\end{array}$ & 0 & $0 \%$ \\
$1 \mathrm{H} 3$ & $\begin{array}{l}\text { Students knew how to investigate by formulating conjectures, } \\
\text { i.e. they recognised that observed patterns were just } \\
\text { conjectures and might not be true. }\end{array}$ & 0 & $0 \%$ \\
$1 \mathrm{H} 2$ & $\begin{array}{l}\text { Students knew how to investigate by examining empirical data, } \\
\text { e.g. evaluating the numerical values of some powers. }\end{array}$ & 14 & $48 \%$ \\
$1 \mathrm{H} 1$ & $\begin{array}{l}\text { Students did not know how to investigate but did something. } \\
\text { For example: } \\
\text { - Students just wrote superficial or irrelevant things. }\end{array}$ & 9 & $31 \%$ \\
& $\begin{array}{l}\text { - Students just evaluated some powers and then did nothing } \\
\text { or could not even find the simplest patterns. }\end{array}$ & & \\
& $\begin{array}{l}\text { Students did not write anything. } \\
\text { Total }\end{array}$ & 6 & $21 \%$ \\
\hline
\end{tabular}

Table 2 shows the second rubric which described what students investigated in the first task. There were also five levels. If students investigated or found trivial patterns such as 'powers of 9 are divisible by 9', they will be placed in Level 1W1 because this shows that they did not know what to investigate. Levels $1 \mathrm{~W} 2$ to $1 \mathrm{~W} 4$ are for different complexities of non-trivial patterns which students investigated or discovered. Wrong conjectures were also included because the process of formulating conjectures was also important, even if the conjectures turned out to be false. If a student discovered more than one pattern, then the level of attainment was the level of the more complicated pattern. It is important to note that 
the patterns described in the scoring rubric were just exemplars and not all of them were discovered by the students. A stratified sample consisting of about $10 \%$ of the students' answer scripts was given to a former teacher, who had a Master's degree in mathematics education and experience in coding qualitative data, to grade. The inter-rater reliability of $88 \%$ was rather high, partly because these rubrics were not so complicated and partly because enough exemplars were given in the descriptors.

Table 2

A Scoring Rubric to Describe What Students Investigated for Task 1

\begin{tabular}{|c|c|c|c|}
\hline Level & Descriptors and Exemplars & $\begin{array}{l}\text { No. of } \\
\text { Students }\end{array}$ & Percentage \\
\hline $1 \mathrm{~W} 4$ & $\begin{array}{l}\text { Students investigated or discovered very complicated patterns, } \\
\text { which might be wrong. For example: } \\
\text { - The last two digits of the powers of } 9 \text { repeat themselves } \\
\text { after } 10 \text { times. } \\
\text { The last two digits of the powers of other single-digit } \\
\text { numbers also repeats itself but after different numbers of } \\
\text { times. }\end{array}$ & 0 & $0 \%$ \\
\hline $1 \mathrm{~W} 3$ & $\begin{array}{l}\text { Students investigated or discovered moderately complicated } \\
\text { patterns, which might be wrong. For example: } \\
\text { - The last digit of the powers of other single-digit numbers } \\
\text { also repeats itself but after different numbers of times. } \\
\text { - When multiplying two powers of } 9 \text {, the indices are added } \\
\text { together to give the index of the resulting power of } 9 \text { (law } \\
\text { of indices). }\end{array}$ & 1 & $3 \%$ \\
\hline $1 \mathrm{~W} 2$ & $\begin{array}{l}\text { Students investigated or discovered non-trivial but simple } \\
\text { patterns, which might be wrong. For example: } \\
\text { - Powers of } 9 \text { are odd. } \\
\text { - The last digit of the powers of } 9 \text { repeats itself after } 2 \text { times. } \\
\text { - Powers of } 9 \text { are divisible by factors of } 9 \text {. } \\
\text { - The sum of all the digits of powers of } 9 \text { is divisible by } 9 \text {. } \\
\text { - Odd powers of } 9 \text { contain at least one digit } 9 \text { and even } \\
\text { powers of } 9 \text { contain no digit } 9 \text { (the latter is false since } 9^{12} \\
\text { contains one digit } 9 \text { ). } \\
\text { - } 9^{n} \text { has } n \text { digits (which is false since } 9^{22} \text { has } 21 \text { digits). }\end{array}$ & 8 & $28 \%$ \\
\hline $1 \mathrm{~W} 1$ & $\begin{array}{l}\text { Students did not know what to investigate but did something. } \\
\text { For example, } \\
\text { - Students just wrote superficial or irrelevant things and did } \\
\text { not discover anything. } \\
\text { - Students investigated or discovered trivial patterns such as: } \\
- \text { Powers of } 9 \text { are divisible by } 9 \text { or are multiples of } 9 \text {. } \\
- \text { When a power of } 9 \text { is divided by } 9 \text {, the result is the } \\
\text { preceding power of } 9 \text {. } \\
\text { - When the index of a power of } 9 \text { is increased by } 1 \text {, the } \\
\text { new number is the same as multiplying the original } \\
\text { power of } 9 \text { by } 9 \text {. }\end{array}$ & 14 & $48 \%$ \\
\hline $1 \mathrm{~W} 0$ & $\begin{array}{l}\text { Students did not write anything. } \\
\text { Total }\end{array}$ & $\begin{array}{c}6 \\
29\end{array}$ & $\begin{array}{l}21 \% \\
100 \%\end{array}$ \\
\hline
\end{tabular}




\section{Findings}

Before analysing the students' answers, it was worthwhile to describe what happened in the classroom just after the start of the test. Within five minutes, five students raised their hand and asked me what they were supposed to do for the first investigative task. I told them to read the sample questions but they replied that they did not understand these questions. Although I would very much like to explain the task requirement further, I refrained from doing so, partly because the purpose of this test instrument was to see if the students knew how and what to investigate when given this kind of open investigative tasks, and partly because I would not be the one administering the test and answering students' questions if the test was given to a large sample of students. I will now analyse how and what these students investigated.

\section{Mathematical Investigative Task 1: Powers of a Number}

Table 1 in the previous section shows the number and percentage of students who achieved each level for Task 1. Six students wrote nothing (Level 1H0), probably because they did not understand what it meant to find any patterns. The workings of another nine students showed that they did not know how to investigate. For example, four of them wrote superficial stuff such as 'the pattern is $91,92,93,94,95$ which will continue' or '96 $=9 \times 9 x$ $9 \times 9 \times 9 \times 9$ ' without evaluating the powers; five of them did find the numerical values of some powers of 9 , but two of them just stopped there while the other three said that they could not find any patterns, not even simple patterns such as 'all the powers of 9 are odd' or 'the last digit alternates between 1 and 9'. In total, 15 out of the 29 students (or 52\%) did not know how to investigate by examining empirical data (Levels $1 \mathrm{H} 0$ to $1 \mathrm{H} 1$ ). The remaining 14 students knew how to investigate, but there were no attempts to justify why the patterns worked (Level 1H2). No students attained Levels $1 \mathrm{H} 3$ or $1 \mathrm{H} 4$.

Table 2 in the previous section shows that six students wrote nothing (Level 1W0), while 14 students wrote something but they did not know what to investigate, e.g. six of them observed trivial patterns such as 'powers of 9 are divisible by 9' or 'when a power of 9 is divided by 9, the result is the preceding power of 9' In total, 20 out of the 29 students (or $69 \%$ ) did not know what to investigate (Levels $1 \mathrm{~W} 0$ to $1 \mathrm{~W} 1$ ).

The remaining nine students were able to find some non-trivial patterns although most of them (i.e. eight students) only investigated or observed rather simple non-trivial patterns 
(Level 1W2). It was surprising that only four students discovered that 'the last digit alternates between 1 and 9' since this was one of the more obvious patterns. Two of these four students also examined the last digit of powers of other numbers: one of them investigated powers of 6 and powers of 2 , and concluded that powers of different numbers had their own patterns but did not identify the patterns; the other discovered that 'the last digit of powers of 4 is always 4', but after evaluating the first few powers of 5, he concluded that 'the pattern for powers of 9 does not apply to powers of 4 and powers of 5'. It seems that this student interpreted the suggested problem at the end of the task statement, "Do these patterns occur for powers of other numbers?" to mean whether the exact pattern for the last digit of powers of 9 applies to powers of other numbers. He was unable to see beyond this specific pattern to the general pattern that the last digit of powers of any number repeats itself. These two students were classified under Level 1W2 instead of Level 1W3 because the latter level required the students to be proficient in investigating the last digit of powers of other numbers but it was doubtful that these two students knew what they were doing. None of the students investigated the patterns for the last two digits (Level 1W4). Three students also discovered that 'the sum of the digits of powers of 9 is divisible by 9', which was rather unexpected because such pattern would not have existed if powers of 2, 4, 7 or 8 (with a period of 4 for the repeating pattern) were used in Task 1 instead. One of the three students shed some lights as to why he investigated the sum of the digits:

Student: As I have read a book on Maths, I remembered that the sum of the digits in each number adds up to a multiple of 9 .

Two of the above three students who discovered about the sum of the digits of powers of 9 also investigated the sum of the digits of powers of 2 and powers of 3, and concluded that the sum of the digits of powers of 3 is divisible by 3 . The remaining student investigated powers of 4 , but stopped after evaluating 42 and 43 . Therefore, only a total of five students (or 17\%) investigated powers of other numbers, including the previous two students who examined the last digit of powers of other numbers.

There were also two wrong but interesting conjectures made by two other students. One of them concluded that 'odd powers of 9 contain at least one digit 9 but even powers of 9 do not contain any digit 9'. However, he based his finding on the first 10 powers of 9, but the next even power of 9, 912, contains a digit 9. Another student believed that ' $9 \mathrm{n}$ has $\mathrm{n}$ digits'. This student also stopped at the first 10 powers of 9, but 922 has 21 digits only. Both students 
did not realise that they could not generalise by looking at only a few cases without any justification.

Only one student discovered a moderately complicated pattern (Level 1W3): a law of indices which the class had not studied before. The working of the student also suggests that he had not learnt this law from elsewhere because he wrote the following to describe what he was doing.

Student: Trying to multiply the powers to see if they make out another power.

In the end, the student discovered that $9 m \times 9 n=9 m+n$. This finding was rather similar to a research study conducted by Lampert (1990). During a series of lessons, a class of fifth-grade students were investigating squares when they discovered some patterns in the last digit of the squares. Lampert then made use of the students' discoveries to extend the problem to "What is the last digit of 54? 64? 74?" and later to "What is the last digit of 75 ? 767778 ?" The students were unsure of how to obtain 78 from 74 . This eventually led to the discovery that the indices should be added together when multiplying powers with the same base.

\section{Mathematical Investigative Task 2: Basketball Tournament}

This task had a guiding problem in part (a) and students were free to investigate anything in part (b). Due to space constraint, it is not possible to provide the two scoring rubrics for the task, so the main findings will be described instead. For part (a), 20 out of 29 students (or 69\%) obtained the correct answer by using $19+18+17+\ldots+1=190$. This was not surprising since this was a common problem for primary school students, and 22 of these students had indicated in the post-test survey that they had seen or solved this part-question or a similar question. Of the remaining nine students, five made some careless mistakes while four got the concept wrong by doing direct multiplication such as $20 \times 19=380$ matches.

For part (b), the issue was whether the students knew how and what to investigate when no problem was given. In particular, did the students try to generalise? Three students wrote nothing for part (b) while 15 students posed irrelevant or poor questions such as "how many players score in one team?" or "how many players are there altogether if there are 11 players in each of the 20 teams?" The solution for the latter problem is just multiplication, which is structurally different from the solution for part (a). In total, 18 out of the 29 students (or $62 \%$ ) were unable to pose relevant or good problems to investigate, despite the guiding 
problem in part (a). Of the remaining 11 students, 10 of them posed some relevant problems, but not those that tend towards generalisation. For example, five students posed a similar question as part (a), except that two changed the context while three changed the numbers. For the latter, the three students stopped at the question without attempting to see if there was any pattern that could lead to generalisation. Therefore, an overwhelming 28 out of the 29 students (or 97\%) did not try to generalise. Only one student attempted some kind of generalisation. He tried to find a pattern between the number of teams and the total number of matches they had to play against each other. In a way, this was trying to generalise the total number of matches for different numbers of teams, but he got part (a) wrong, meaning he just took 20 teams x 19 matches per team $=380$ matches, so his pattern in part (b) was also incorrect.

\section{Mathematical Investigative Task 3: Polite Numbers}

This task had no scaffolding and students were expected to pose their own problems to investigate. The structure of this task was more similar to that of Task 1 because both tasks involved looking for any patterns. I will first look at how the students investigated. Four students wrote nothing and six students wrote irrelevant or superficial things such as if $\mathrm{c}=2$ $+3+4+5$, then we can find $\mathrm{c}=14$ ' or 'what is the sum of $9+11+18$ ?' Nine students started with some random natural numbers and attempted to express them as sums of consecutive natural numbers to find out whether they are polite or to discover some other patterns. In total, 19 out of the 29 students (or 66\%) did not know how to investigate by systematically listing the sums of consecutive natural numbers to sieve out the polite numbers or to discover other patterns. For the remaining 10 students, only three explained why their conjectures were correct while one proved that his conjecture was wrong based on a counter example.

I will now look at what the students investigated. Four students wrote nothing, and nine students wrote incorrect trivial results such as 'the polite numbers kept on increasing from 9 to 11 to 18 and could not decrease' (which was false). Another six students observed trivial patterns such as 'all numbers cannot be polite numbers' and 'to find the next polite number for say, $6=1+2+3$, just add 4 , i.e. $1+2+3+4=10^{\prime}$ (but 10 is not the next polite number after 6). In total, 19 out of the 29 students (or 66\%) did not know what to investigate. For the remaining 10 students, four investigated which numbers are polite or impolite, e.g. two of them found out that 'all odd numbers are polite but not all even numbers are polite'. [All odd numbers except ' 1 ' are polite.] Another five students tried to find a pattern for 
successive polite numbers that are sums of two (or three) consecutive numbers, e.g. one of them proved that 'the difference between successive polite numbers that are sums of two consecutive numbers is always 2 , and the difference between successive polite numbers that are sums of three consecutive numbers is always 3'. The last student tried to find out 'whether a bigger number can be expressed as a sum of consecutive numbers in more ways than a smaller number' since one of the examples given in the task was expressed as a sum in two ways (this is called the degree of politeness), but unfortunately, he misinterpreted what polite numbers were because his sums were sums of distinct natural numbers and not consecutive numbers. None of the students examined more complicated patterns such as the difference between successive polite numbers that are sums of more than three consecutive numbers, nor attempted to find a pattern for impolite numbers.

\section{Mathematical Investigative Task 4: Amazing Race}

The usual phrasing of a similar closed problem-solving task for this question is to find out which person will win the race given a scenario. But to make the closed problem-solving task into an open investigative task, two options were given in part (a) and students were asked to investigate the difference between the two options; and for part (b), students were to think of some other options for the race which they could investigate.

For part (a), it was very surprising that three students wrote that the difference between the two options was that Bernard was $10 \mathrm{~m}$ in front of the start line in the first option while Ali was $10 \mathrm{~m}$ behind the start line in the second option, which was exactly what the task stated! Equally surprising was one student who argued that there was no difference between the two options since the distances of the two runners from the start line were both $10 \mathrm{~m}$, i.e. it did not matter to this student that one runner was starting $10 \mathrm{~m}$ after the start line while the other runner was starting $10 \mathrm{~m}$ before the start line! Nine other students said that the difference between the two options was the different distances that the runners had to run, i.e. both runners needed to run $10 \mathrm{~m}$ more in the second option than in the first option. In fact, three of these nine students said that Ali would have to use up more energy to run the longer distance of $110 \mathrm{~m}$ in the second option. Another student claimed that there was no difference because Bernard had to run $10 \mathrm{~m}$ less than Ali in both options. Four other students did not write anything. In total, 18 out of the 29 students (or 62\%) did not realise that the crucial difference between the two options was how they would affect who would win the race. Another two students said that there was no difference without giving any reason, so it was 
not possible to judge whether they knew this crucial difference or not. Of the remaining nine students, seven reasoned wrongly that both options would end in a draw, and only two students were able to argue correctly that the first option would end in a draw while Ali would win in the second option. In other words, only two out of the 29 students (or 7\%) answered part (a) correctly.

For part (b), 11 students wrote nothing. Another 11 students suggested a trivial option to investigate, e.g. four of them wanted Bernard to run $10 \mathrm{~m}$ before Ali starts running, but this was the same as Bernard starting $10 \mathrm{~m}$ after the start line which was the first option stated in part (a). Another five students wanted the faster runner Ali to run on the outer lane of a curved track with both starting at the same start line and ending at the same end line, but it was puzzling that these five students wrote that Ali would have more distance to run and yet they still called it a $100-\mathrm{m}$ race or a $100-\mathrm{m}$ curved track. Anyone who has watched athletic meets on TV can tell you that 100-m races are always on the straight portions of the track while the starting points for $400-\mathrm{m}$ races are different for all the runners precisely because of the curved track. In total, 22 out of the 29 students (or 76\%) did not know what to investigate for part (b). The remaining seven students were able to suggest a non-trivial option for the race. One of them suggested the faster runner to reduce his speed by a certain amount and so you have to recalculate who will win the race. Another claimed it was fair that the faster runner should start $5 \mathrm{~m}$ behind the start line while the slower runner should start $5 \mathrm{~m}$ after the starting line. Two other students wanted the faster runner to start $10 \mathrm{~m}$ after the starting line, while the slower runner to start $20 \mathrm{~m}$ after the start line. The last three students suggested giving the slower runner a head start of a certain timeframe such as two or three seconds, but one of the three students recommended a few minutes' head start! The latter did not seem to have a sense of how long it would take to run $100 \mathrm{~m}$. In fact, two other students drew a $100-\mathrm{m}$ oval track for part (a), suggesting that they might not have any idea how long the oval tracks in a stadium were. It seems that some of these students were not able to connect the real world to school mathematics.

\section{Post-test Written Survey}

Seventeen students (or 59\%) commented in the post-test written survey that the test was difficult. Of these 17 students, only three of them said that the challenge was good for them while the rest did not state explicitly whether they viewed the difficulty positively or 
negatively. However, another six students wrote very negative comments about the test, three of which were reprinted below.

Student 1: $\quad$ I feel it is pretty useless and a waste of my time.

Student 2: I think I am going to fail. I think that I am going to be scolded as I don't

know how to do the questions as it is so \# $\square$ !!@ing hard. I think that [the test] was good as it help [sic] me to find out that I'm dumb.

Student 3: Boring, Very Uninteresting, No motive to complete, time wastes [sic] Can be improve [sic] a lot.

Nevertheless, there were six positive comments, including the three who said that the difficulty was good for them. Only three of these comments were reproduced below.

Student 4: This test was fun and I enjoyed myself. It was fun to investigate and I would not mind another test.

Student 5: $\quad$ It is very challenging. It requires your brain and your knowledge and experience. Like, have you come across this sum before? I think I would like to practice some questions like this. It helps us to exercise our brains.

Student 6: It was interesting. But there should have been more time given as the questions were quite challenging.

\section{Discussion}

The data analysis shows that most of the high-ability students in the present study did not know how and/or what to investigate. The first problem is the failure to understand what it means to investigate. Even when sample problems were given in Task 1, many of them still did not know what to do. This may be because the suggested problem about finding as many patterns as possible about powers of 9 was too general for the students. In Singapore, students are familiar with solving specific problems by looking for patterns, e.g. Task 2(a), but looking for any patterns without having a problem to solve had confounded many students in this study. It seems that the absence of a specific problem results in the students' inability to understand the task requirement, thus resulting in $52 \%$ of the students not knowing how to investigate and $69 \%$ of the students not knowing what to investigate for Task 1 . The students also fared badly in the other three tasks: $62 \%$ were not able to pose relevant or good problems to investigate in Task 2(b) despite the guiding problem in part (a); 66\% did not know how to investigate by systematic listing in Task 3; and 76\% did not know what to investigate in Task 4(b).

The second problem is the inability of most of the students to pose their own problems to investigate. Students in Singapore are familiar with solving problems but they are seldom tasked to pose their own problems to solve. Krutetskii (1976) argued that there is a problem 
that 'naturally follows' from the given task, and he found that high-ability students were able to pose it directly but low-ability students were not able to do so unless they were given hints. However, most of the students in the present study were not able to do so. For example, $86 \%$ did not try to discover a pattern in the last digit of powers of 9 in Task 1; $97 \%$ did not attempt to find a general formula for the number of matches in Task $2 ; 86 \%$ did not try to find out which numbers in Task 3 are polite or impolite; and $62 \%$ were unable to investigate the crucial difference between the two given options in Task 4(a). There may be another reason why some of these students did not pose non-trivial problems to investigate. Mason et al. (1985) was concerned that some students may pose only problems that they can solve. In the present study, a student stated this intention explicitly:

Student: I think I constructed [sic] a simple investigation that can be solved easily.

Although the other students did not write this explicitly, this may be a real issue because in traditional classrooms, the goal is to obtain the correct answer and getting stuck is usually considered a drawback. So there may be a tendency for some of these students to pose trivial problems that they can solve easily.

If many of the high-ability students in the present study did not know how and what to investigate, then average and low-ability students may encounter even greater difficulty in such written tests on open investigation although there may be exceptions. This suggests that the current level of proficiency in open investigation among Singapore secondary school students is very low. Although further research is needed to substantiate this, it is not advisable to continue using this kind of paper-and-pencil test for other students because it may result in more students hating open mathematical investigation, judging from the many adverse reactions from the students in the current study.

\section{Implications for Research and Teaching}

Open mathematical investigation and closed problem solving are indeed very different. For the former, students without prior experience do not know what the task requirement is and so they cannot even start; for the latter, although students may not know how to solve the problems, they can at least start trying because they know the goal is to solve the problems. For problem solving, simpler problems can be included at the beginning to give the students some confidence before giving the more difficult problems, but for open investigation, it is not easy to make the tasks simpler. Instead of the word 'investigate', a 
more specific question 'find as many patterns as possible' in Task 1 was still too general for the high-ability students in this current study to understand the task requirement; and a sample problem in part (a) of Task 2 also did not help these students to know what to investigate for part (b). As a result, the more guided investigative Tasks 1 and 2 did not help the students to understand the task requirement of the more open investigative Tasks 3 and 4 .

Therefore, this poses a serious dilemma for researchers on how they can assess students' current level of competency in open investigation. It is unethical to give a paperand-pencil test to a large group of students after knowing that this may cause many of them to loathe open investigation. Even for research using a teaching experiment with a small group of students, it will not be surprising if the students perform significantly better in the written post-test than in the pre-test, as this is the consequence of the students not understanding the task requirement in the pre-test, and not necessarily because the teaching experiment is effective in developing the various thinking processes in open investigation.

Hence, it is necessary to rethink how to measure the efficacy of a teaching experiment in open investigation. One suggestion is not to begin with a pre-test but with a familiarisation programme so that students know what it means to investigate when given an open investigative task. Once the students have understood the task requirement, they can then be given a paper-and-pencil pre-test, followed by a teaching experiment with the aim of developing in students the many different processes in open investigation. In this way, students may not perform significantly better in the post-test if the teaching experiment is not effective in cultivating these processes in the students; but any significant difference between the pre-test and the post-test can then be attributed to the effectiveness of the teaching experiment.

Teachers may know that students need to be taught how and what to investigate when given open investigative tasks, but they may think that students can cope with questions asking them to find as many patterns as possible. The present study has revealed that students may have great difficulty finding any patterns when there is no specific problem to solve, unlike finding patterns to solve a specific problem. So there is still a need for teachers to teach their students how to search for any patterns. 


\section{Conclusion}

We learn not only from the success of a research study. In fact, we can learn valuable lessons from the failure of the paper-and-pencil test on open investigation in the present study. For example, the current study has shed some light on the inadequacy of a pre-test on open investigation that is administered before a teaching experiment, or a stand-alone written test on open investigation as a research methodology, although a similar test instrument for closed problem solving can still work quite well. Therefore, there is a need to rethink whether we should measure students' current or initial level of competency in open investigation before any teaching experiment.

The present study has also revealed the low level of proficiency in open investigation among secondary school students in Singapore. Since there are valuable processes that can only be developed more fully in open investigation, such as problem posing and searching for any patterns to understand the underlying mathematical structures, then Singapore students should be exposed to this kind of investigation, but local teachers may not be ready to teach this since most of them do not understand what open investigation is (Yeo, 2008). Moreover, further research needs to be done to find out more about the nature and development of processes in open investigation so as to inform teachers on how to plan and design suitable open investigative tasks and teaching strategies to develop these processes in their students.

\section{References}

Australian Education Council. (1991). A national statement on mathematics for Australian schools. Melbourne: Curriculum Corporation.

Bailey, J. (2007). Mathematical investigations: A primary teacher educator's narrative journey of professional awareness. In J. Watson \& K. Beswick (Eds.), Proceedings of the 30th annual conference of the Mathematics Education Research Group of Australasia (MERGA): Mathematics: Essential research, essential practice (Vol. 1, pp. 103-112). Adelaide, South Australia: MERGA.

Cai, J., \& Cifarelli, V. (2005). Exploring mathematical exploration: How two college students formulated and solve their own mathematical problems. Focus on Learning Problems in Mathematics, 27(3), 43-72.

Christiansen, B., and Walther, G. (1986). Task and activity. In B. Christiansen, A. G. Howson, \& M. Otte (Eds.), Perspectives on mathematics education: Papers submitted by members of the Bacomet Group (pp. 243-307). Dordrecht, The Netherlands: Reidel.

Cockcroft, W. H. (1982). Mathematics counts: Report of the committee of inquiry into the teaching of mathematics in schools under the chairmanship of Dr W H Cockcroft. London: Her Majesty's Stationery Office (HMSO).

Ernest, P. (1991). The philosophy of mathematics education. London: Falmer Press. 
Evans, J. (1987). Investigations: The state of the art. Mathematics in School, 16(1), 27-30. Frobisher, L. (1994). Problems, investigations and an investigative approach. In A. Orton \& G. Wain (Eds.), Issues in teaching mathematics (pp. 150-173). London: Cassell.

HMI. (1985). Mathematics from 5 to 16. London: Her Majesty's Stationery Office (or HMSO).

Jaworski, B. (1994). Investigating mathematics teaching: A constructivist enquiry. London: Falmer Press.

Krutetskii, V. A. (1976). The psychology of mathematical abilities in school children. In J. Kilpatrick \& I. Wirszup (Series Eds.), Soviet studies in the psychology of learning and teaching mathematics. Chicago: University of Chicago Press.

Lampert, M. (1990). When the problem is not the question and the solution is not the answer: Mathematical knowing and teaching. American Educational Research Journal, 27, 2963.

Lee, M., \& Miller, M. (1997). Real-life math investigations: 30 activities that help students apply mathematical thinking to real-life situations. New York: Scholastic Professional Books.

Mason, J., Burton, L., \& Stacey, K. (1985). Thinking mathematically (Rev. ed.). Wokingham, England: Addison-Wesley.

Ministry of Education of Singapore. (2000). Mathematics syllabus: Lower secondary. Singapore: Curriculum Planning and Development Division.

$\mathrm{Ng}, \mathrm{H}$. C. (2003). Benefits of using investigative tasks in the primary classroom. Unpublished master's thesis, National Institute of Education, Nanyang Technological University, Singapore.

Orton, A., \& Frobisher, L. (1996). Insights into teaching mathematics. London: Cassell.

Pirie, S. (1987). Mathematical investigations in your classroom: A guide for teachers. Basingstoke. UK: Macmillan.

Pólya, G. (1957). How to solve it: A new aspect of mathematical method (2nd ed.). Princeton, NJ: Princeton University Press.

Tanner, H. (1989). Introducing investigations. Mathematics Teaching, 127, 20-23.

Yeo, J. B. W. (2008). Pre-Service teachers engaging in mathematical investigation. In Electronic Proceedings of the Asia-Pacific Educational Research Association (APERA) Conference 2008: Educational Research for Innovation \& Quality in Education: Policy \& Pedagogical Engagements Across Contexts. Singapore: APERA and Educational Research Association of Singapore (ERAS).

Yeo, J. B. W., \& Yeap, B. H. (2010). Characterising the cognitive processes in mathematical investigation. International Journal for Mathematics Teaching and Learning: online journal available at http://www.cimt.plymouth.ac.uk/journal. 

Southeast Asian Mathematics Education Journal 2014, Vol. 4 No. 1 